\title{
Estructura del lenguaje científico antiguo-medieval
}

\author{
José Martínez GázQuez ${ }^{1}$
}

Los aspectos lingüísticos de los textos científicos, especialmente en los textos antiguos y medievales, podrían tener un tratamiento específico en relación a la secuencia, hablada o escrita, en que se producen, por la peculiaridad de la formulación a que están sometidos. Se produce esta situación en la evolución y desarrollo del lenguaje cientifico en esta etapa histórica ante su necesidad de expresión y los precarios medios concretos de que dispone para ello. El análisis de la estructura del texto en tanto que lenguaje científico, según las pautas que nos ofrece un reciente trabajo de aplicación de la lingüistica textual a los textos científicos medievales, ofrece un destacado interés que queremos subrayar a través de la aplicación de los elementos esenciales de dicha teoria al texto de la Additio latina de los Cánones para las Tablas astronómicas alfonsíes de Juan de Sajonia. Seguimos la presentación y los pasos señalados en el trabajo de Georg Bossong, "Vers une syntaxe textuelle du discours scientifique médiéval». Cahiers de linguistique hispanique médiévale, 7, 1982, 91-125.

Se resaltan en dicho trabajo las peculiaridades del discurso científico y la forma en que tales características trascienden el ámbito de una lengua concreta sin depender de su estructura particular, sino que se pueden establecer en un nivel de concreción y aplicación universal. La lectura de los textos científicos antiguos y medievales, y acaso de los textos científicos de todo tiempo, produce una impresión dominante en el lector, pues sobresale su carácter analítico y lineal en el más alto grado

\footnotetext{
1 Universidad Autónoma de Barcelona.
} 
y, por otra parte, produce una sensación de prolijidad extrema. Tal carácter analítico, por lo demás, se muestra en el texto tanto en el nivel conceptual, como en el nivel sintáctico, según subraya G. Bossong.

La razón de estas peculiaridades tan destacadas en la plasmación escrita del lenguaje científico se debe en gran medida al estadio concreto del desarrollo de la expresión científica. En sus primeros estadios el contenido científico necesariamente se expresa en progresión lineal, exigida por la secuenciación compleja, paso a paso, de las formulaciones científicas ante la ausencia de otro tipo de formulaciones. En el campo de las ciencias matemático-astronómicas de la época antigua y medieval no se cuenta con la presencia de tipo alguno de formulación algebraica. Por ello la ciencia de estas etapas se caracteriza por la verbalización total de todo lo que más tarde se expresó a través de la fórmulas.

Los procesos de operaciones se van explicando paso a paso. El cálculo de unos datos concretos sólo es posible avanzando por descomposición de las operaciones integrantes; hay que llegar a una secuencia ordenada de las operaciones a realizar, las cuales continúan desarrollándose de forma lineal y progresiva. En definitiva, la descripción de un cálculo complejo se estructura en la enumeración de las operaciones individuales con secuencias verbales lineales secuencialmente progresivas. Se resalta en el trabajo indicado que la ausencia de letras en las notaciones científicas conlleva el carácter analítico conceptual, y la ausencia de símbolos técnicos queda en la base de su carácter analítico, sintáctico y textual.

Desde este punto de vista el análisis lingüístico y filológico de la lengua de los textos científicos medievales, al que se ha prestado muy escasa o nula atención, adquiere una importancia relevante y el estudio de las traducciones de estos textos científicos presenta matices no contemplados hasta ahora desde esta perspectiva por la nueva servidumbre que imponen al traductor los contenidos mismos que traduce.

Habiendo realizado recientemente la edición del texto de los Cánones de las Tablas astronómicas de Alfonso $X$ el Sabio de Juan de Sajonia (Publicaciones de la Universidad de Murcia, 1989), podemos constatar la verificación de estos extremos en un capítulo de la Additio que presentan dichos cánones en el texto latino y en su traducción castellana anónima de finales del siglo XV, que evidencia una dependencia total del original latino.

\section{A.6. Latitudinem Veneris per tabulas inuenire.}

Scias centrum cuius equatum et argumentum equatum et unumquodque per se serua; deinde cum ipsius uero argumento intra tabulas eius in 
linea numeri et accipe quod inueneris in directo in tabula declinationis et reflexionis et unumquodque seorsum scribe; postea centro Veneris 60 gradus adde quod, si post additionem prouenerint ultra 360 gradus, proiice 360 et cum residuo uel cum eo quod fuerit minus 360 ingredere easdem lineas numeri et quod in eius directo inueneris de minutis proportionalibus sume et serua. Deinde accipe partem proportionalem declinationis prius seruate secundum proportionem minutorum proportionalium ad 60. Et hec erit latitudo eius primo examinata, que prouenit ex declinatione epicycli et serua eam. Si autem centrum uerum, cum quo operatus est, et argumentum uerum, id est, argumentum uerum et centrum uerum cum suo addito erunt in eadem parte circuli, id est, si ambo fuerint in medietate superiori aut ambo in medietate inferiori, erit ipsa latitudo equata meridiana. Et si unum istorum fuerit in una medietate et aliud in alia erit ipsa latitudo septemtrionalis ... et residuum erit latitudo Veneris uerificata septemtrionalis meridionalis.

\section{A.6. La longura de Venus por las tablas fallar}

"Sabe su çentro ygualado y el argumento ygualado y cada uno por si guardar; de ende entra las sus tablas con su verdadero argumento en la linea del numero y toma lo que fallares en derecho en la tabla de la declinaçion y reflexion; escriue fazia el cada una cosa; despues añade al çentro de Venus 60 grados lo qual si despues de la adiçion proviniere allende de 360 grados alcança los 360 y con lo sobrado o con aquello que fuere menos de 360 grados entra las mesmas lineas del numero y lo que en su derecho fallares de los minutos proporçionales toma y guarda y en ende toma la parte proporçional de la declinaçion primero guardada según la proporçion de los minutos proporçionales a los 60 . $Y$ aquesta <erit> su anchura primero examinada, la qual proviene de la declinaçion del epiçiclo y guardala. Mas si el çentro verdadero con el qual obras y el argumento verdadero y <id est, argumentum uerum et> el centro verdadero con su añadimiento seran en esa misma parte del çirculo, <id est> si anbos estubieren en la meytad superior o anbos en la meytad ynferior sera esa anchura ygualada meridional. $Y$ si uno de estos estoviere en una meytad y el otro en otra, sera esa anchura septentrional ...... lo que queda sera la anchura de Venus verificada septentrional o meridional'.

Siguiendo, pués, la nomenclatura y estructuración mencionada, recordemos brevemente las nociones aplicables al análisis del texto, de las que las principales son las siguientes: 
$\mathrm{T}=$ Tema, es el equivalente a la información conocida.

$\mathrm{R}=$ Rema, aporta la información nueva.

$\mathrm{PL}=$ Progresión lineal, cuando el rema de una frase constituye el tema de la siguiente.

PTC $=$ Progresión de tema constante, cuando permanece el mismo tema en varias frases.

PRE = Progresión de rema escindido, cuando un rema implícita o explícitamente queda dividido en dos o más.

PRC = Progresión de rema circular, cuando recogiendo el tema o rema inicial y después de una secuencia de progresiones se resalta el resultado alcanzado.

Ejemplificando con elementos tomados del capítulo 6 de la Additio latina mencionada, tenemos:

$T=$ Latitudinem Veneris per tabulas inuenire.

La longura de Venus por las tablas fallar

$\mathrm{R}=$ Scias centrum cuius equatum et argumentum equatum et unumquodque per se serua;

Sabe su çentro ygualado y el argumento ygualado y a cada uno por si guardar;

$\mathrm{PL}=$ deinde cum ipsius vero argumento intra tabulas eius in linea numeri et accipe quod inueneris in directo in tabula declinationis et reflexionis et unumquodque seorsum scribe; postea centro Veneris 60 gradus adde quod,

de ende entre las sus tablas con su verdadero argumento en la linea del numero y toma lo que fallares en derecho en la tabla de la declinaçion y reflexion; escriue fazia el cada una cosa; después añade al çentro de Venus 60 grados, 10 qual

PREa $=$ si post additionem prouenerint ultra 360 gradus, proiice 360 si despues de la adiçion proviniere allende de 360 grados, alcança los 360

$\mathrm{b}=$ et cum residiuo uel cum eo quod fuerit minus 360 ingredere easdem lineas numeri et quod in eius directo inueneris de minutis proportionalibus sume et serua.

y con lo sobrado o con aquello que fuere menos de 360 grados entra las mesmas lineas del numero y lo que en su derecho fallares de los minutos proporçionales toma y guarda 
Deinde accipe partem proportionalem declinationis prius seruate secundum proportionem minutorum proportionalium ad 60 .

y de ende toma la parte proporçional de la declinaçion primero guardada segun la proporçion de los minutos proporçionales a los 60 .

Et hec erit latitudo eius primo examinata.

$Y$ aquesta <erit> su anchura primero examinada,

PTC = que prouenit ex declinatione epicycli, et serua eam.

la qual proviene de la declinaçion del epiçiclo, y guardala.

PREa = Si autem centrum uerum, cum quo operatus est, et argumentum uerum, id est, argumentum uerum et centrum uerum cum suo addito erunt in eadem parte circuli, id est,

Mas si el çentro verdadero con el qual obras y el argumento verdadero y <id est, argumentum uerum et $>$ el centro verdadero con su añadimiento seran en esa misma parte del çirculo, <id est>

$a^{\prime}=$ si ambo fuerint in medietate superiori aut ambo in mediatate inferiori, erit ipsa latitudo equata meridiana.

si anbos estubieren en la meytad superior a anbos en la meytad ynferior sera esa anchura ygualada meridional.

$\mathrm{b}=$ Et si unum istorum fuerit in una mediatate et aliud in alia erit ipsa latitudo septentrionalis ...

$Y$ si uno de estos estoviere en una meytad y el otro en otra, sera esa anchura septentrional ...

PCR $=\ldots$ et residuum erit latitudo Veneris uerificata septemtrionalis meridionalis.

... lo que queda sera la anchura de Venus virificada septentrional o meridional.

Con ello se constituye una estructuración global del discurso, en la que el tema o rema inicial designa generalmente el problema, la incógnita que se quiere resolver, enunciada al inicio, y el rema final, recogiendo el problema inicial, suma los resultados de las operaciones realizadas y señala la resolución de la incógnita propuesta en el tema inicial. Se indica también de esta forma que las operaciones han llegado a su fin obteniendo el resultado buscado. Se consigue, en definitiva, la circularidad de la estructura a través de una serie de progresiones lineales.

Este esquema global, y las progresiones encerradas en él, no dependen, en principio, de la estructura individual de una lengua concreta. Subyace un fondo de contenido semejante a todas que impone su necesidad de expresión en todos los casos. Lingüísticamente cada lengua empleará para realizar dicha estructura los medios adaptados y conformes con sus propias características, pero condicionada por el desarrollo lineal de las operaciones científicas expresadas. 
El carácter analítico en la síntaxis del texto científico emplea algunos procedimientos entre los que destacan:

1. Sintagmas nominales de dos categorias:

a) Términos técnicos de las ciencias analizadas que asumen sintácticamente funciones de objeto directo 0 atributo en oraciones de verbo copulativo. Estos términos técnicos son el soporte de las operaciones matemáticas y quedan especificados en la traducción castellana, por ejemplo, en la reiteración de reflexivos-posesivos; en elementos deícticos para reforzar la referencia anafórica en un contexto: «... y aquesta "será" su anchura primero examinada".

b) La aparición necesaria, como exigencia gramatical, de un sujeto agente con el que concierta el verbo que expresa la operación científica indicada. Lingüísticamente queda reflejado por la segunda persona del singular, que asume una especie de función generalizadora anónima que alude al posible sujeto agente que en cada caso perciba el mensaje y sea por tanto usuario de la fórmula indicada: Scias centrum cuius ... et accipe quod inueneris...

2. Limitación extrema de formas temporales y modales de los verbos empleados. En la oración principal puede presentar el texto latino futuro de indicativo, a veces substituido por el imperativo y el verbo subordinado siempre traducido por futuro de subjuntivo: ... et quod in eius directo inueneris de minutis proportionalibus sume et serua. Deinde accipe... "...Y lo que en su derecho fallares de los minutos proporcionales toma y guarda. $Y$ de ende toma...»

En las explicaciones intercaladas (PTC) el tiempo del verbo es el presente de indicativo con valor no temporal: Et haec erit latitudo eius primo examinata que prouenit ex declinatione epicycli.

El lenguaje resulta así reiterativo y monótono llevado por la expresión verbal lineal del proceso a seguir, sin la posibilidad de emplear la expresión sintética de las fórmulas modernas. La expresión se muestra de esta forma absolutamente paralela en el texto latino y en la traducción castellana. Con respecto a ésta última podemos considerar que a las deficiencias de un traductor poco avezado y poco conocedor de la lengua latina, se le han sumado la dificultades de la expresión misma del contenido 
científico. Éste le marca unas pautas de expresión lineal y secuencial, para cuyo mantenimiento se ha visto constreñido el traductor a sacrificar un estilo más literario y libre y sobre todo más comprensible para el lector o usuario de los cánones. 